\title{
A Argumentação e a Análise Linguística nas Aulas de Jnglês como Língua Estrangeira: estudo de caso de uma atividade para aprendizes iniciantes de língua inglesa
}

\author{
Thiago Magno de Carvalho COSTA* \\ Erivaldo Pereira do NASCIMENTO** \\ José Wellisten Abreu de SOUZA***
}

\footnotetext{
* Mestre em Linguística pela Universidade Federal da Paraíba (UFPB). Doutorando no mesmo Programa. Atualmente é Secretário Executivo Bilíngue lotado no CCHLA - UFPB, Campus I. Contato: magnodecarvalho@gmail.com. ** Doutor em Letras pela Universidade Federal da Paraíba (2005). Realizou Estágio de Pós-Doutorado na Universidad de Buenos Aires - Argentina (2014), com financiamento CAPES/MEC. Atualmente é Professor Associado da UFPB. Contato: erypn@hotmail.com.

*** Doutor em Linguística pela Universidade Federal da Paraíba (UFPB). Atualmente está como Professor Substituto Adjunto A na UFPB, Campus I. Contato: josewellisten@hotmail.com.
}

\begin{abstract}
Resumo:
Este artigo apresenta uma análise sobre a possibilidade de se trabalhar atividades com gêneros textuais partindo das duas concepções de argumentação: a retórica e a linguística. Para tanto, como fundamentação teórica, buscamos a associação entre a proposta de Ducrot $(1987,1988)$, com ênfase para os postulados da Teoria de Argumentação na Língua, e a perspectiva de Análise Linguística, conforme proposta por Geraldi (1984, 1997). Nesse contexto, é válido justificar o livro didático de língua inglesa como importante corpus de análise, por acreditarmos que, nesse material de apoio, é possível constituir, a partir da atividade selecionada, uma análise de natureza qualitativa, de base descritiva e com caráter propositivo, que nos permita apresentar uma reflexão, a título de colaboração, acerca da possibilidade de se trabalhar nos gêneros textuais as duas concepções de argumentação. Observa-se que trabalhar o texto proporciona ao estudante o contato com variados textos, os quais, de fato, circulam na sociedade. Em suma, a análise reflexiva aqui proposta para a atividade do livro didático e as sugestões de ampliação visam contribuir com os estudos e as pesquisas da Semântica Argumentativa, a partir da abordagem de procedimentos que auxiliam o trabalho do professor de inglês como língua estrangeira.
\end{abstract}

Palavras-chave:

Análise Linguística. Ensino de inglês. Argumentação.

Signum: Estudos da Linguagem, Londrina, v. 21, n. 2, p. 199-219, ago. 2018 


\section{A Argumentação e a Análise Linguística nas Aulas de Inglês como Língua Estrangeira: estudo de caso de uma atividade para aprendizes iniciantes de língua inglesa}

Thiago Magno de Carvalho Costa; Erivaldo Pereira do Nascimento; José Wellisten Abreu de Souza

\section{INTRODUÇão}

O estudo de uma língua tem importantes implicações em várias instâncias educacionais. Nesse sentido, é possível também afirmar que uma compreensão adequada acerca da estrutura, da aquisição e do uso de uma determinada língua é essencial para o ensino de uma segunda língua e/ou de uma língua estrangeira. Pode-se, ainda, dizer que também é possível promover uma compreensão acerca da variação e do uso da língua na sala de aula e contribuir para os diversos debates já existentes acerca de temas que envolvem o ensino e o aprendizado de uma língua estrangeira.

É sabido da existência, do desenvolvimento e do aprimoramento de várias abordagens de ensino de segundas línguas e de línguas estrangeiras com o foco nos gêneros textuais. Todas as abordagens possuem algo a oferecer e, teoricamente, qualquer uma delas possui enormes chances de sucesso se houver ao menos um professor capacitado (nativo ou não), alunos motivados, suporte pedagógico, equipamentos apropriados e uma estrutura física adequada.

Assim como vem acontecendo com o ensino de língua portuguesa, o trabalho com os gêneros textuais ocupa um papel importante também nas aulas de língua inglesa. Conforme os Parâmetros Curriculares para ensino de língua estrangeira (BRASIL, 1998), "os conteúdos [de língua estrangeira] estão organizados em torno de quatro eixos: conhecimento de mundo, conhecimento sistêmico, tipos de texto e atitudes" (p. 71). Isso acontece de forma gradativa quando, no primeiro e no segundo ciclos (do $1^{\circ}$ ao $5^{\circ}$ ano do Ensino Fundamental), o foco é envolver o aprendiz na construção do significado, enfatizando, assim, o seu engajamento discursivo e cultural. Na sequência, isto é, no terceiro e no quarto ciclos (do $6^{\circ}$ ao $9^{\circ}$ ano), "pode-se aumentar a proporção de conhecimento sistêmico da Língua Estrangeira, posto que o aluno já terá desenvolvido a capacidade de se engajar no discurso via Língua Estrangeira" (p. 72), fazendo com que os componentes sistêmicos (a gramática, o léxico, por exemplo) sejam incluídos na programação a partir das escolhas dos temas e dos textos a serem abordados em sala de aula.

Entretanto, mesmo com a existência de teorias da ciência da linguagem sobre o texto e o discurso que, de uma forma ou de outra, dão suporte ao professor no ensino da 
compreensão do sentido produzido pelo uso da língua estrangeira, parece ainda haver muito pouca aplicação de estudos acerca das estratégias de argumentação no texto, em língua estrangeira, na sala de aula e, principalmente, nos livros e manuais didáticos atualmente disponíveis.

Este artigo teve como ponto de partida algumas inquietações provenientes das discussões acerca de materiais didáticos, realizadas nas reuniões do Grupo de Pesquisa "Semântica, Léxico e Cognição", ${ }^{1}$ nas quais percebemos a ausência, na maioria das vezes, de um estudo sobre os aspectos linguísticos mobilizados na construção da trama argumentativa dos gêneros textuais em livros didáticos de língua inglesa utilizados em cursos livres de idiomas e em escolas de ensino regular. O nosso objetivo, neste artigo, é apresentar uma reflexão, a título de colaboração com os autores de livros didáticos de língua estrangeira sobre a possibilidade de se trabalhar, nas atividades com os gêneros textuais, as duas concepções de argumentação: a retórica e a linguística.

Essa reflexão, também fundamentada na perspectiva da Análise Linguística (cf. GERALDI, 1984), está pautada na análise da subseção "Can you understand this text?", que faz parte da seção "Revise and Check" da Unidade $7^{2}$ do livro New English File - Elementary (OXENDEN; LATHAM-KOENIG; SELIGSON, 2010), bastante utilizado pelos professores de língua inglesa aqui no Brasil, através da qual intencionamos trazer possibilidades de apresentar questões concernentes à argumentação, focando na Análise Linguística, presentes no artigo de jornal apresentado pelo livro didático.

Com o presente trabalho, esperamos contribuir com os estudos da Semântica Argumentativa através da análise da relevância dos elementos linguísticos na leitura de textos em língua inglesa, além de contribuir com o ensino de língua estrangeira, de uma forma geral, em função de tratar-se de uma análise de livros didáticos. Com o intuito de obter uma melhor apreensão do sentido construído pela linguagem, vimos a necessidade de trabalhar com alguns aspectos da Teoria da Argumentação na Língua (TAL), proposta por Oswald Ducrot $(1987,1988)$ e colaboradores, na sua versão standard, tendo em vista ser uma teoria, em linhas gerais, que parte da premissa de que a argumentação está marcada na própria língua. Com isso, refletiremos sobre a contribuição da Semântica Argumentativa, a partir da investigação acerca da concepção (retórica e/ou linguística) que embasa a atividade. Desse modo, analisaremos a atividade proposta e explicaremos a importância da apresentação de aspectos linguísticos com base na teoria que fundamenta o trabalho. Não temos a intenção de rechaçar nenhuma das concepções presentes na atividade do livro didático, muito menos dizer que ela não está apropriada para o nível de competência linguística dos alunos, contudo,

\footnotetext{
${ }^{1}$ Disponível em: < https://bit.ly/2yrsHxI>.

${ }^{2}$ A unidade do material didático foi selecionada para análise mediante o critério de escolha pelo gênero textual artigo de opinião.
} 
buscamos perceber quais aspectos são relevantes para o incremento da capacidade argumentativa dos estudantes.

Nas duas próximas seções, faremos algumas considerações: (a) sobre a Análise Linguística (AL) (cf. GERALDI, 1984) e (b) sobre a argumentação, aspectos estes que consideramos importantes para a nossa análise (Nova Retórica, TAL, os operadores argumentativos e a modalização). Na terceira seção, descreveremos o encaminhamento da atividade proposta pelo livro didático em questão, bem como desenvolveremos as análises interpretativistas da atividade, a partir do referencial teórico adotado.

Enfim, antes das considerações finais, apresentaremos a nossa contribuição, com propostas de questões que seguem a perspectiva da AL, na tentativa de enriquecer a atividade já previamente indicada.

\section{Sobre a ANÁlise Linguística}

Desde que a Linguística passou a fazer parte do currículo universitário de Letras, nos últimos quarenta anos, vem se concebendo, mesmo que de forma incipiente, a aplicação de uma prática pedagógica a qual conhecemos por Análise Linguística (AL). O termo Análise Linguística foi cunhado por Geraldi $(1984)^{3}$ para denominar uma nova perspectiva de reflexão sobre o sistema linguístico e sobre os usos da língua, com vistas ao tratamento escolar de fenômenos gramaticais, textuais e discursivos. O que configura um trabalho de AL é a reflexão recorrente e organizada, voltada para a produção de sentidos e/ou para a compreensão mais ampla dos usos e do sistema linguístico. Nas palavras do autor,

Entendo por prática de análise lingüística a recuperação, sistemática e assistemática, da capacidade intuitiva de todo falante de comparar, selecionar e avaliar formas lingüísticas e a prática de produção de textos com uso efetivo e concreto da linguagem com fins determinados pelo locutor ao falar e escrever (GERALDI, 1984, p. 79).

Nesse sentido, destacam-se atividades tanto de produção de textos como de leitura de textos, no interior das quais e a partir das quais se propõe uma análise reflexiva sobre a linguagem.

Relevantemente, a aplicação da AL tem se tornado bastante próspera para aqueles docentes e pesquisadores que, assim, a adotaram em suas aulas ou em suas investigações a respeito do ensino tanto de língua materna como de língua estrangeira. Entretanto, grande parte dos professores de língua inglesa ainda ativos no mercado de trabalho teve, em sua formação, pouco contato com essa prática, até mesmo porque muitos deles não foram

\footnotetext{
${ }^{3}$ Esse referencial origina-se da língua materna, contudo está sendo considerado neste trabalho com a Língua Estrangeira, levando em conta o ensino da língua/linguagem no sentido mais geral.
} 
sequer apresentados à Linguística como ciência da linguagem. Igualmente, ao ingressarem no mercado de trabalho, esses mesmos professores se depararam como uma escola enraizada nos métodos tradicionais e com práticas focadas no ensino apenas da metalinguagem, problema agravado pela resistência à mudança; isto é, alguns dos docentes que estão em sala de aula há, pelo menos, quinze, vinte anos, desconsideram as perspectivas do ensino epilinguístico por não se sentirem seguros em aplicar essa tendência no ensino de língua estrangeira, sem esquecer das inúmeras prescrições (a exemplo da metodologia utilizada, as regras internas da escola, a coordenação etc.), às quais estes docentes são submetidos a depender do contexto em que estão inseridos. Tal compreensão pode ser justificada com base em pesquisa feita por Sousa e Soares (2012, p. 90), na qual as autoras sugerem que "a abordagem tradicional ainda predomina dentro das salas de aula de língua estrangeira".

A respeito das atividades metalinguísticas e epilinguísticas, tomando por base Geraldi (1997, p. 24-25), podemos dizer que as primeiras são atividades voltadas ao conhecimento do sistema da língua. Aqui se propõe uma análise da língua(gem) com relação à construção de conceitos, classificações etc. A pertinência é definir parâmetros mais ou menos estáveis para decidir sobre questões como erro/acerto no uso. Por outro lado, as segundas são atividades que se constituem de "operações" que se manifestam nas negociações de sentido. São atividades que congregam aspectos estruturais da língua, como também aspectos discursivos, tendo como foco a reflexão sobre a língua que se usa. No entanto, percebemos que duas práticas vêm demonstrando uma coexistência em sala de aula: a prática tradicional e o "passo para a mudança". Segundo Mendonça (2006, p. 200), verifica-se que, "neste momento histórico, do início do $3^{\circ}$ milênio, as práticas de ensino [...] revelam (como sempre revelaram) um mescla de perspectivas: o jeito 'tradicional' de ensinar gramática ainda está presente, ao passo que novas práticas também já são encontradas".

O ensino da norma padrão não deve ser rechaçado das aulas de língua estrangeira, assim como não deve ocorrer a mera substituição do termo "ensino de gramática" por "reflexão sobre e uso da língua", para que não se torne apenas uma troca de terminologias. O ensino de língua deve ser direcionado de forma que o aluno possa compreender os textos produzidos nas diversas situações interacionais, fazendo a relação dos conceitos gramaticais com as práticas de leitura e escrita, resultando, assim, em um aluno que utiliza e reflete bem acerca da língua. Parafraseando Geraldi (1984), não é preciso que o professor faça uso das nomenclaturas ou da classificação dos operadores argumentativos ou dos modalizadores, por exemplo. Isso implica saber que os aspectos linguísticos dos textos com características argumentativas devem ser trabalhados não como mais um conteúdo 'gramatical', mas na perspectiva da epilinguagem, possibilitando que os alunos aprendam a refletir sobre os sentidos que esses aspectos provocam na trama argumentativa.

Entretanto, há uma demora natural para que o conhecimento produzido na academia seja apropriado pelos profissionais que atuam diretamente na Educação Básica. Isso se soma ao fato de que nem todas as instituições formadoras estão no mesmo patamar de qualidade, sem falar que os profissionais atuantes no mercado já há algum tempo têm tido 
pouco ou nenhum contato com novas formas de pensar e fazer. Por outro lado, positivamente falando, é preciso que fique o registro de que há iniciativas da academia e dos professores em sala de aula para tentar diminuir esse distanciamento entre pesquisa e prática docente, a fim de acabar por vez com essa letargia na condução de um problema que persiste após tantos anos.

Por isso, mesmo que os Parâmetros Curriculares Nacionais (PCN) para língua estrangeira não digam claramente, é preciso que estejamos conscientes de que a argumentação é inerente aos mais variados gêneros textuais, sobretudo àqueles com características opinativas, a exemplo do artigo de opinião, e deve, portanto, ser trabalhada constantemente e de forma adequada, independentemente do nível linguístico do estudante de língua estrangeira. Vale ressaltar, contudo, a identificação da argumentação enquanto organização tipológica básica, necessária ao arranjo composicional de vários gêneros textuais presentes em diferentes práticas sociais e linguageiras da vida cotidiana. Conforme Koch (2011), no processo de intelecção dos textos com os quais temos contato na vida cotidiana desenvolve-se a competência textual de um falante, a qual lhe permite diferenciar determinados gêneros, isto é, saber se se está diante de uma anedota, um poema, um anúncio publicitário etc., bem como averiguar se em um gênero predominam sequências de caráter narrativo, descritivo, expositivo e/ou argumentativo. Logo, o que definirá a escolha por um determinado gênero, marcado pela predominância de uma dada tipologia são, justamente, "as esferas de necessidade temática, o conjunto dos participantes e a vontade enunciativa ou intenção do locutor" (p. 54). Desse modo, o que se prescreve nos PCN (BRASIL, 1998) é a ideia de o professor, recorrendo, inclusive, ao material didático de apoio, estimular o aluno a perceber qual a sequência tipológica predominante na organização de um dado texto, seja oral ou seja escrito, a ser selecionado e abordado em sala.

A seguir, apresentaremos um panorama de alguns aspectos das teorias da argumentação, a exemplo da Teoria da Argumentação na Língua (TAL) que, entre as várias correntes teóricas dos estudos da linguagem, pode fornecer elementos importantes para um ensino focado nos aspectos mais epilinguísticos, especialmente por considerar o sistema (a estrutura) da língua, a partir de sua relação com o uso, uma vez que é uma teoria que integra aspectos pragmáticos na descrição linguística.

\section{Sobre a ArgumentaÇão: da Nova Retórica à Teoria da ArgumentaÇão na Língua}

Chaïm Perelman encontrou, nos antigos tratados da retórica aristotélica, a possibilidade de conceber a argumentação centrada no auditório, isto é, naqueles de quem se espera a adesão ao que é dito. A Nova Retórica, como passou a ser denominada a sua teoria, não se preocupa com as abordagens especificamente linguísticas, pois se interessa mais pelo estudo empírico das técnicas argumentativas, ou seja, preocupa-se com a força, a intensidade e a solidez de um argumento. Na teoria de Perelman (1999), para que a argumentação seja possível, é necessário que ocorra uma espécie de comunhão intelectual 
entre o locutor e o interlocutor, a qual ocorre, dentre outros fatores, principalmente, se a argumentação estiver inserida em um determinado contexto e em um lugar específico e se ela for dirigida a um determinado auditório.

Diante disso, temos que, na concepção de argumentação retórica de Perelman, não importa se as premissas são estabelecidas como verdadeiras ou falsas; o importante é que elas sejam bastante convincentes ou persuasivas, a fim de ganhar a adesão do auditório (NASCIMENTO; SILVA, 2011). Entretanto, Perelman não aprofundou a questão do papel da língua na argumentação, pois o foco dos seus estudos voltou-se para a argumentação factual, e não linguística. Essa perspectiva é abordada por Oswald Ducrot $(1987,1988)$ e seus colaboradores na Teoria da Argumentação na Língua (TAL), que se opõe às teorias e às práticas defendidas pelos estudos retóricos.

Segundo Almeida (2001), Ducrot baseia-se nos estudos sobre enunciação para se opor ao modelo tradicional de argumentação retórica - em que a argumentatividade é dependente dos fatos -, propondo um modelo de semântica que considera a argumentação como um processo inscrito e próprio da língua, visto que falamos para o construir o mundo e a partir disso tentar convencer o nosso interlocutor da nossa "verdade". Desse modo, o ato de enunciação deve ter, para sua eficácia, funções argumentativas, ou seja, podemos usar a linguagem de modo a levar o interlocutor a uma determinada conclusão, ou desviar-se dela. Nas palavras de Ducrot (1988, p. 64, tradução nossa),

a frase em si não é indicação da relação entre os interlocutores e toda a teoria sobre a argumentação pretende justificar esta ideia. O objetivo é mostrar que a frase e, portanto, a língua contém alusões à atividade da fala, contém alusões acerca do que fazemos quando falamos.

Neste trabalho não daremos conta de apresentar toda a teoria do semanticista; no entanto, apresentaremos os conceitos mais importantes para a nossa análise. Para Ducrot (1988), as três concepções tradicionais de sentido - ou aspectos - do enunciado (objetivo, subjetivo e intersubjetivo), nem sempre são possíveis de distinguir. Por isso, ele desconsiderou os aspectos que descrevem a realidade (objetivos) e reuniu os aspectos que mostram a atitude do locutor (subjetivos) e aqueles que se referem às relações locutor-interlocutor (intersubjetivos) e os denominou de valor argumentativo. Desse modo, Ducrot (1988, p. 51, tradução nossa) considera "o valor argumentativo como nível fundamental da descrição semântica".

Observa-se assim, que o valor argumentativo dos enunciados se refere à orientação dada pela palavra ao discurso, sendo o que direciona as possibilidades ou impossibilidades de continuação discursiva, determinadas pelo seu uso. O valor argumentativo dos segmentos do discurso também depende dos enunciadores, que são os pontos de vista, argumentativamente orientados.

A TAL considera que a argumentatividade está na própria estrutura da língua, nas suas frases, ou seja, a língua proporciona aos seus usuários a materialização da 
argumentatividade cada vez que eles transformam essas frases em enunciados, através de estratégias argumentativas. Dentre esses elementos que funcionam como estratégias argumentativas estão os operadores argumentativos. Koch (2000, p. 44) ressalta que "a importância dos operadores argumentativos reside na contribuição para construção do sentido, responsáveis que são pela orientação argumentativa do texto". Os operadores argumentativos, na concepção de Ducrot, são aqueles responsáveis pela ligação de segmentos de um enunciado com o propósito de direcionar o interlocutor a uma conclusão. Ducrot diz que esse termo foi criado para "designar certos elementos da gramática de uma língua que têm por função indicar ('mostrar') a força argumentativa dos enunciados, a direção (o sentido) para o qual apontam" (apud KOCH, 2000, p. 30).

Na concepção de Ducrot, o 'mas' é operador argumentativo por excelência, o qual possui algumas particularidades. Vejamos, então: se tivermos dois segmentos X e Y coordenados pelo operador 'mas' ( $\mathrm{X}$ mas $\mathrm{Y}$ ), teremos as seguintes indicações:

- que existe uma conclusão R que pode ser facilmente encontrada pelo interlocutor, sugerida por X e não confirmada por $\mathrm{Y}$, ou seja, $\mathrm{X}$ e Y apresentam orientações argumentativas opostas em relação à conclusão R;

- que a força de $\mathrm{Y}$ contrária a $\mathrm{R}$ é maior que a força de $\mathrm{X}$ a seu favor, fazendo com o que X' mas Y' seja orientado no sentido de não-R.

Para melhor ilustrar a explicação anterior, descreveremos o enunciado a seguir através da polifonia de enunciadores ou masPA ${ }^{4}$ (DUCROT, 1988):

\section{Mike has studied hard but won't pass the exam. ${ }^{5}$}

(Mike estudou bastante, mas não será aprovado no exame).

Nesse enunciado, identificamos os seguintes enunciadores: (a) E1 'Mike estudou bastante', que acredita no potencial de Mike, representado pelo locutor L, mas com o qual ele não se identifica; (b) E2, que direciona, a partir da intensidade dos estudos de Mike, para um certo otimismo (esse enunciador é a conclusão R 'Mike terá sucesso', que é rechaçada por L); (c) E3 'mas não será aprovado no exame', que é o ponto de vista que apresenta a dificuldade do exame ao qual Mike foi submetido (esse enunciador opõe-se a E1 e é apresentado por L, que se identifica com ele); e (d) E4 que, a partir da não aprovação de Mike, conclui que há um certo pessimismo. O enunciador E4 é a conclusão não-R 'Mike não terá sucesso', que é também um ponto de vista com o qual L se identifica. Portanto, podemos dizer que L aprova E1, rechaça E2 e se identifica com E3 e E4.

\footnotetext{
4 “Para Vogt e Ducrot (1980, p. 104), o conectivo masPA, de função argumentativa, não exige necessariamente que a proposição anterior $p$ seja negativa. Para esses linguistas, sua função é introduzir uma proposição $q$ que orienta para uma conclusão não-r oposta a uma conclusão $r$ para qual $p$ poderia conduzir. Trata-se, portanto, de um indicador de polifonia" (NASCIMENTO, 2009, p. 33).

${ }^{5}$ Decidimos por exemplos em inglês em virtude da temática deste trabalho.
} 
O que se apresentou no enunciado anterior, conforme a TAL, foi a marcação, pelo operador 'mas' (but), de uma oposição entre duas conclusões possíveis. A oposição não se encontrou entre os segmentos em si, isto é, não são os conteúdos destes ligados pelo 'mas' que se opõem, mas, sim, à conclusão para a qual cada um deles direciona (DUCROT, 1981). Assim, vemos que a forma como os operadores argumentativos se articulam no discurso traça o caminho a ser seguido pelas perspectivas enunciadas até as conclusões.

De acordo com os estudos de Ducrot (1988), a organização dos operadores argumentativos é percebida através da classe argumentativa e da escala argumentativa. A classe argumentativa é constituída por elementos que podem servir igualmente como argumentos que apontam para uma mesma conclusão, e a escala argumentativa é a gradação de força crescente dos enunciados de uma classe no sentido de uma mesma conclusão. Assim, para Ducrot (cf. CABRAL, 2010), o locutor de um enunciado pode hierarquizar os argumentos de uma classe argumentativa.

Apenas para exemplificar, se tivermos um enunciado como: Peter is an ambitious politician. He wants to be not only the mayor but also the president (Pedro é um político ambicioso. Ele quer ser não apenas o prefeito, mas também o presidente), observamos que os operadores em destaque estabelecem uma hierarquia dos segmentos em uma escala, assinalando que o argumento 'ser presidente' é o mais forte dentro da classe de argumentos apresentados, orientando, assim, para a conclusão de que Pedro é um político ambicioso. A hierarquia na escala de argumentos pode ser assim descrita:

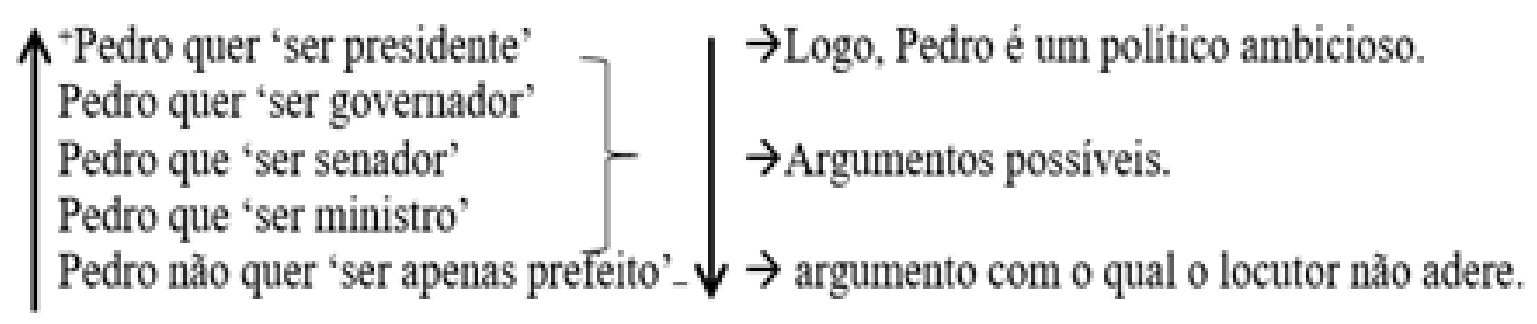

Fonte: Elaborada pelos autores.

\section{Figura 1}

A classe e a escala argumentativa permitem perceber como os operadores estão organizados em suas forças para produzirem um sentido desejado pelo locutor do discurso. Essas forças ora atuam como reforço, soma da argumentação anterior, ora como contraposição, ora como fechamento de uma ideia, para citarmos apenas alguns exemplos. A leitura é direcionada justamente através do valor argumentativo que conduz o interlocutor a chegar às conclusões construídas pelas pistas criadas pelo locutor.

Outro fenômeno argumentativo apresentado pela TAL é o discurso relatado ou RED (relato em estilo direto, cf. DUCROT, 1987, p. 186), que "procura reproduzir na sua materialidade as palavras produzidas pela pessoa de quem se quer dar a conhecer o discurso", 
ilustrando o caso clássico da polifonia de locutores $(\mathrm{L})^{6}$. As marcas linguísticas que identificam a polifonia de locutores, na língua e no discurso, são as aspas, o travessão, os dois pontos e os verbos dicendi ${ }^{7}$, entre outras.

Além desses elementos, a língua, conforme a TAL, nos fornece outros termos, estruturas para que possamos utilizar e que funcionam diferentemente. Dentre essas estratégias, tem-se os modalizadores. Na maioria dos casos, os advérbios exactly, often etc. são os termos mais utilizados para marcar a modalização na trama argumentativa. Igualmente, alguns verbos - tais como could, might, must etc. - e até mesmo alguns adjetivos podem funcionar como modalizadores, cumprindo, assim, um papel importante na organização e na articulação de um texto argumentativo. Todavia, ressaltamos que um mesmo elemento linguístico pode expressar diferentes tipos de modalização, gerando, portanto, diferentes efeitos de sentido. Para Silva (2012), os modalizadores podem ser identificados como "todos os elementos linguísticos que funcionam como indicadores das intenções, dos sentimentos e das atitudes do enunciador no que diz respeito a seu discurso" (p. 54). Castilho (2010), por sua vez, sugere que quando "o falante avalia o teor de verdade da proposição, ou expressa um julgamento sobre a forma escolhida para a verbalização desse conteúdo" (p. 553) estamos diante do processo da modalização. Vejamos:

a) Realmente Cuiabá é uma cidade muito quente.

b) Talvez eu vá a Recife nas próximas férias.

c) Ela provavelmente vai se demitir da empresa amanhã.

Esses exemplos demonstram o modo como advérbios podem funcionar como elementos modalizadores. Os autores dos manuais didáticos, quando trabalham com esses fenômenos, podem levar o aluno a perceber a função importante que tais elementos imprimem em uma oração, em um período, ou até mesmo em um texto inteiro. Como é possível observar, o papel dos modalizadores é orientar, discursivamente, a argumentação pretendida por aquele que produz o enunciado. Logo, dizer que "Cuiabá é uma cidade muito quente" não expressa, ainda, tudo o que um locutor que diz 'a' quer dizer. Parece, por implicatura ${ }^{8}$, que, antes de estar em Cuiabá, tal locutor sabia do calor apenas de ouvir falar.

\footnotetext{
${ }^{6}$ A polifonia é constitutiva do sentido dos enunciados, na perspectiva de Ducrot (1988) e colaboradores. Manifesta-se pela presença de diferentes pontos de vista (em enunciadores) ou diferentes locutores, no enunciado. O locutor é aquele 'ser' que, no próprio sentido do enunciado, aparece como responsável pela enunciação (aquele que se apresenta como responsável pelo enunciado).

${ }^{7}$ Conforme Corbari e Ramos (2018, p. 2908), os verbos dicendi são um dos recursos utilizados para sinalizar o discurso citado, permitindo incorporá-lo ao texto. Logo, os verbos dicendi (ou verbos do dizer) são introdutores do discurso direto e indireto.

${ }^{8}$ De acordo com Moura (2006, p. 13), a implicatura é uma das formas de inferência que focaliza as intenções pretendidas pelo interlocutor em relação ao locutor. Pressuposto e implicatura são tipos de inferência situados claramente em níveis diferentes de interpretação. "O pressuposto [...] deve ser inferido [...] a partir do conhecimento compartilhado, e não da intenção do locutor” (p. 52).
} 
Estando na cidade, sentindo na pele a quentura, muda-se a enunciação, havendo como confirmar o fato com certeza. A esse respeito, em geral, os modalizadores são classificados ${ }^{9}$ em: (i) epistêmicos, (ii) deônticos, (iii) avaliativos e (iv) delimitadores. A título de complementação, deixamos a reflexão de Nascimento (2012, p. 6):

Em determinados textos, a observância dos modalizadores é de fundamental importância para a construção de um sentido mais global do próprio texto. Por essa razão, quando da ocorrência de modalizadores, o professor deve orientar seus alunos para considerar os efeitos de sentido que esses geram, bem como de que maneira esses interferem para a compreensão global.

Portanto, vê-se que a identificação do sentido que certos elementos dão ao texto, como um todo, faz parte do conjunto de habilidades que um usuário de uma língua precisa ter a fim de que seja considerado competente linguisticamente.

$\mathrm{Na}$ seção seguinte, faremos as análises das atividades dos livros didáticos, aos quais nos referimos nas nossas Considerações Iniciais.

\section{Sobre a Análise da Atividade e as Sugestões de Acréscimos de Questões}

Ter o LD como suporte amostral nesta pesquisa é de suma importância, pois uma análise crítica pode representar uma oportunidade para o estabelecimento de conhecimentos e ações acerca de uma abordagem reflexiva no ensino de Língua Inglesa, com ênfase para a compreensão de como se manifesta a argumentação em gêneros textuais. Nesse sentido, a escolha por trabalhar com LD se justifica, pois permite estabelecer uma análise qualitativa, de base descritiva e com viés propositivo, em que pese uma delimitação da contribuição e da importância de uma sistematização didática da argumentação, retórica e linguística, bem como, principalmente, a sua relação com a compreensão e a produção de gêneros textuais, de modo que, além disso, estabeleça-se reflexão sobre as abordagens metodológicas no Ensino de Língua Inglesa.

Logo, assume-se o entendimento de que o livro didático fornece aos alunos-leitores "um conjunto de documentos, textuais ou icônicos, cuja observação ou confrontação podem vir a desenvolver o espírito crítico do aluno" (CHOPPIN, 2004, p. 553), haja vista o livro didático ser o principal recurso utilizado em sala de aula pelo professor no processo de ensino-aprendizagem de língua inglesa.

Convém acrescentar que o livro didático é um suporte para o professor e não um fim em si mesmo. Portanto, vale ressaltar que as sugestões aqui apresentadas para a atividade visam promover outras reflexões a respeito do papel da argumentação na constituição de

\footnotetext{
${ }^{9}$ Para uma explicação detalhada, consultar Nascimento e Silva (2012).
} 
textos, possibilitando uma aprendizagem efetiva e eficaz para aluno de inglês como língua estrangeira. Desse modo, promove-se a análise linguística reflexiva, conforme discutimos anteriormente, pela associação entre meta e epilinguagem, desde que se priorize o trabalho com esse segundo tipo de abordagem. Assim sendo, a proposta visa atender ao anseio de que os alunos sejam instrumentalizados a desenvolver habilidades e competências não só voltadas para a decodificação de estruturas linguísticas, mas principalmente voltadas à compreensão de como tais estruturas participam da construção do sentido dos textos.

O livro didático New English File - Elementary, em sua sétima unidade, assim como as demais do livro, apresenta quatro subunidades (7A, 7B, 7C, 7D), nas quais são estudados assuntos referentes à Grammar, Vocabulary e Pronunciation, além das subunidades finais Practical English e Writing. Além disso, no livro didático há uma subunidade final chamada Revise and Check. Esta última contém as seguintes subseções: (i) What do you remember?, que revisa gramática, vocabulário e pronúncia; e (ii) What can you do?, que disponibiliza algumas atividades que auxiliam os estudantes a medir seu progresso em termos de habilidades de leitura, fala e compreensão auditiva. Fazendo parte desta última, tem-se a subseção Can you understand this text?, que selecionamos, tendo em vista que esta poderia ser discutida sob o ponto de vista da argumentação.

No New English File - Elementary, a referida subseção possui um conjunto de cinco questões acerca de um artigo intitulado "Food can be dangerous for your health", adaptado de um jornal britânico, segundo informações do livro didático. Sabe-se que o gênero artigo de opinião não tem a função de divulgar a opinião de uma instituição jornalística, mas sim de transmitir a opinião de quem o produziu. Segundo Melo (2003), a argumentação presente num artigo é baseada no conhecimento e na sensibilidade do articulista e que os julgamentos feitos por ele podem ser provisórios, uma vez que, na maioria dos casos, o artigo trata de assuntos que ainda estão se constituindo. Por isso, é importante que o professor de língua estrangeira, ao apresentar esse gênero textual na sua sala de aula, esteja atento para a forma como o autor direciona a leitura do seu artigo através dos recursos linguístico-discursivos utilizados por ele na composição do seu texto. Para ilustrar, apresentamos, na próxima página, o texto do livro didático.

Pode-se perceber que o artigo é desenvolvido no sentido de emitir um ponto de vista sobre a importância de se saber a quantidade de calorias contidas em cada prato disponível nos cardápios de bares, restaurantes e lanchonetes no Reino Unido. Ao trabalhar um gênero textual como este na sala de aula de língua estrangeira, o professor deverá verificar não só o ponto de vista do articulista, mas também quais recursos (ou estratégias e fenômenos) argumentativos foram utilizados. Ao se trabalhar com gêneros de opinião explícita, como o artigo, nas salas de aula de línguas, estrangeira ou materna, é relevante fazer com que os alunos percebam como os argumentos favoráveis - assim como os contrários, quando existirem - são postos no texto. 


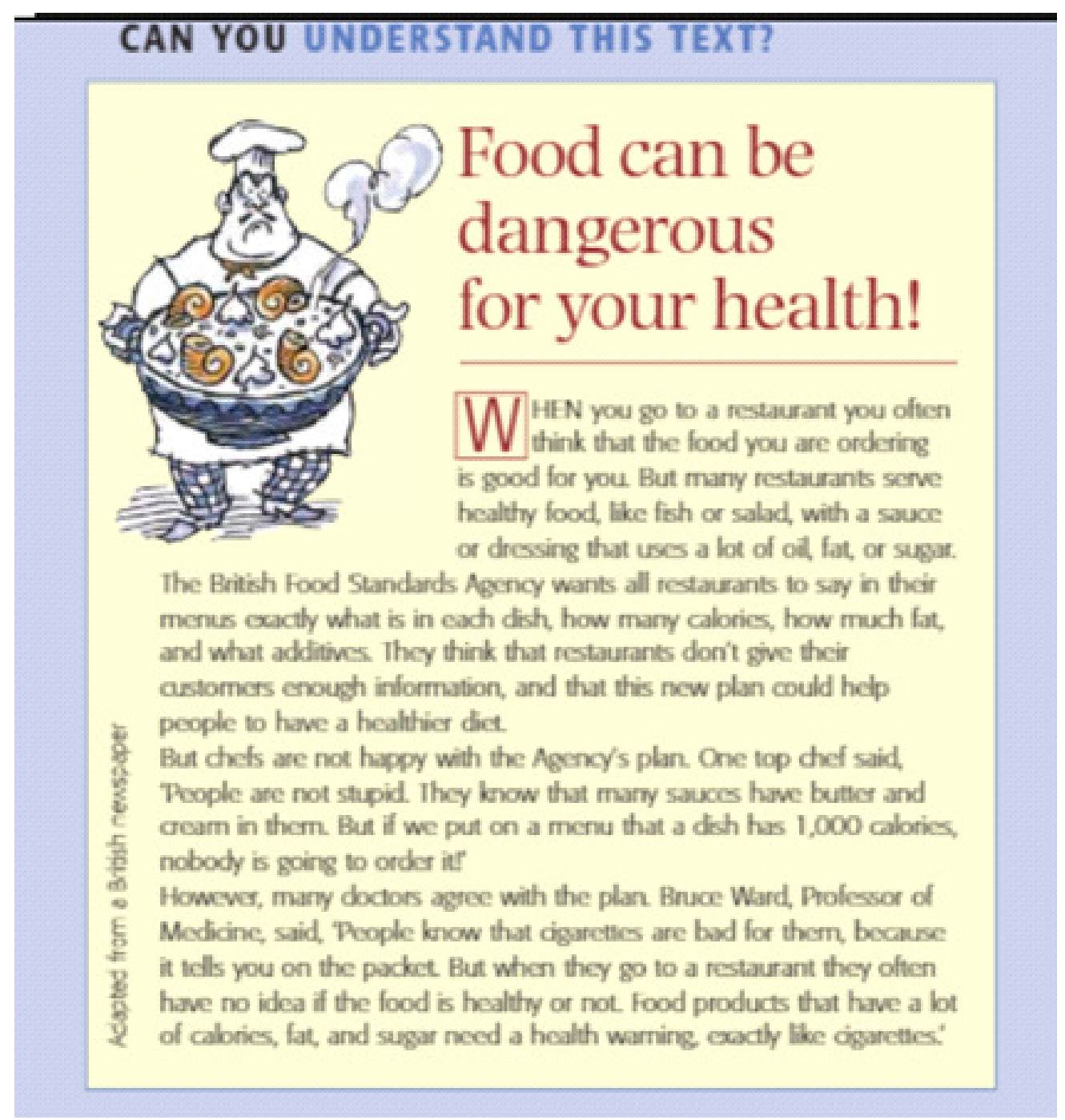

Fonte: Adaptada de Oxenden; Latham-Koenig e Seligson (2010, p. 87).

\section{Figura 2}

Vimos que, após a apresentação do artigo, o livro didático propõe atividades que envolvem estratégias tradicionais de leitura, como skimming ${ }^{10}$, para obter a ideia geral, e scanning ${ }^{11}$, para buscar informações específicas no texto, com o objetivo de reforçar a habilidade de leitura e de aquisição de vocabulário. Isso pode ser comprovado a seguir:

a. Read the article. Circle a, b, or c.

1. Many restaurants...(a) serve healthy food; (b) only serve fish and salad; (c) serve healthy food but with unhealthy sauces;

\footnotetext{
${ }^{10}$ De acordo com Konar (2009, p. 154, tradução nossa), "quando você lê rapidamente sem pausas para estudar detalhes, chamamos isso de leitura skim ou skimming".

${ }^{11}$ De acordo com Konar (2009, p. 154, tradução nossa), "fazer um scanning significa ler o texto lentamente e cuidadosamente à procura de informações específicas nas quais você está interessado".
} 
2. The British Food Standards Agency wants restaurants...(a) to serve healthy food; (b) to give more information about their dishes; (c) not to use fat and additives;

3. Chefs think that...(a) people are not going to order their dishes; (b) people are stupid; (c) cream and butter are good for you;

4. Doctors think that people...(a) need more information about cigarettes; (b) need more information about food; (c) need to stop eating in restaurants;

b. Read the article again. Underline and learn five new words connected with food and cooking (adaptado de OXENDEN; LATHAM-KOENIG; SELIGSON, 2010, p. 87).

É possível perceber que a abordagem apresentada nesta atividade do livro didático em análise, do ponto de vista da argumentação, não promove nenhum empenho em fazer com que os alunos reflitam sobre os aspectos responsáveis pela argumentação no texto, sejam eles retóricos ou linguísticos. Conforme se verifica nas atividades listadas, os autores tentaram problematizar o texto lido, auxiliando os alunos a retomarem o artigo e a atentarem para alguns aspectos considerados importantes para a compreensão do texto; como exemplos, temos as questões presentes na atividade 'a'. Por isso, reforçamos a ideia de que seria preciso verificar os recursos linguístico-discursivos utilizados, a começar pelo título do artigo, quando o articulista escolhe um verbo modalizador deôntico de possibilidade 'can' para já direcionar o leitor para a uma determinada conclusão.

Nas nossas considerações iniciais, informamos que o nosso objetivo não seria rechaçar nenhum tipo de questão apresentada pelo material didático, pois sabemos da relevância das questões de interpretação na formação da competência leitora dos alunos iniciantes de uma língua estrangeira. Além disso, é fundamental que o professor e o livro didático tenham uma preocupação de fazer com que os alunos utilizem os conhecimentos adquiridos através de uma prática reflexiva, promovendo, assim, uma ampliação da capacidade de análise crítica dos estudantes.

Com base no exposto, deixaremos como contribuição algumas possíveis questões que poderiam ser acrescentadas à atividade original, tentando observar a apresentação de ambas as abordagens da argumentação, além de se parametrizar nas concepções reflexivas da AL (cf. GERALDI, 1984), ou seja, uma reflexão recorrente e organizada, voltada para a produção de sentidos e/ou para a compreensão mais ampla dos usos e do sistema linguístico. O nosso objetivo foi unificar, neste acréscimo de questões, as duas abordagens argumentativas, no sentido de mostrar aos alunos os efeitos de sentido gerados pelos elementos linguísticodiscursivos ao longo do texto.

O Quadro 1 mostra algumas sugestões, em negrito, que poderiam ser abordadas na atividade, no que concerne à argumentação linguística e à retórica: 
Quadro 1 - Sugestão de acréscimo de Questões I

a. Read the article. Circle a, b, or c.

1. The text mainly talks about...(a) healthy and unhealthy food; (b) the British Food Standards Agency's decision; (c) the best restaurants in England;

2. In Britain, food people order is...(a) probably unhealthy; (b) certainly unhealthy; (d) necessarily unhealthy;

3. The author...(a) agrees with the British Food Standards Agency; (b) disagrees with the British Food Standards Agency; (c) doesn't have an opinion;

4. Many restaurants...(a) serve healthy food; (b) only serve fish and salad; (c) serve healthy food but with unhealthy sauces;

5. The British Food Standards Agency wants restaurants... (a) to serve healthy food; (b) to give more information about their dishes; (c) not to use fat and additives;

6. The British Food Standards Agency's plan...(a) must help people to have a better life; (b) should help people to have a better life; (c) could help people to have a better life;

7. Chefs think that...(a) people are not going to order their dishes; (b) people are stupid; (c) cream and butter are good for you;

8. Doctors think that people...(a) need more information about cigarettes; (b) need more information about food; (c) need to stop eating in restaurants;

9. Chefs are unhappy with the Agency's plan...(a) and the doctors too; (b) because they agree with the doctors; (c) but the doctors are not.

b. Read the article again. Underline and learn five new words connected with food and cooking.

c. Look at the sentence from the text: “...this new plan could help people to have a healthier diet. But chefs are not happy with the Agency's plan". Try to rewrite the sentence with two other connectors and check if there is any difference in terms of meaning.

Fonte: Elaborado pelos autores.

Nas questões sugeridas como acréscimo, buscou-se solicitar dos alunos, inicialmente, o assunto principal do texto (questão a-1). Em seguida, na questão a-2, tem-se o foco no título do artigo, no qual o autor fez uso de um modalizador deôntico de possibilidade (can), o que já direciona o ponto de vista defendido por ele. Nesse sentido, é possível fazer um paralelo com os advérbios modalizadores utilizados nas respostas (probably, certainly, necessarily). Além disso, vale frisar que também há pistas argumentativas no texto do artigo de opinião, por exemplo, em "But many restaurants serve healthy food [...] that uses a lot of oil, fat, or sugar" apresenta-se uma oposição de ideias inserida pelo operador argumentativo but, o qual nega o pressuposto de que tudo o que é servido em um restaurante de comida saudável faça bem a saúde. Conforme sugerido pelo articulista, um peixe ou uma salada (comidas sabidamente saudáveis) podem vir acompanhadas de molho rico em óleo, gordura e açúcar, alimentos perigosos para a saúde. O próprio plano proposto pela Agência Britânica (British Food Standards Agency) sugere várias marcas linguísticas (pistas) argumentativas, a partir da escolha de itens lexicais que constroem o campo semântico belthier diet, tais como: indicar a quantidade de 
calorias, a quantidade de gordura e de aditivos usados nos pratos, corroborando, dessa forma, o proposto no título do artigo, quanto ao necessário cuidado com a alimentação. $\mathrm{Na}$ questão a-3, há um questionamento acerca do ponto de vista do autor, a fim de mostrar a relevância de uma argumentação retórica. Nessas três primeiras questões sugeridas para a atividade, tomamos como base o escopo teórico-metodológico norteado pela Nova Retórica, no sentido de que em tais questões pretende-se levar o aluno a buscar informações no nível de leitura requerido pela técnica skimming, uma vez que, ao responder questões como as propostas, o aluno extrai do texto as ideias gerais, negociando com os sentidos presentes no texto-base da atividade para, assim, chegar ao convencimento pretendido pelo autor do texto. Ademais, vale ressaltar que na questão a-2 demonstra-se, ainda, uma preocupação com relação aos aspectos linguísticos, que toma como base os pressupostos da TAL, haja vista explorar-se a modalização como fenômeno argumentativo.

$\mathrm{Na}$ sequência, na questão a-6, solicitou-se que os alunos identificassem no texto, através da apresentação dos verbos modalizadores (must, should, could), de que maneira o autor do texto fala sobre a decisão da British Food Standards Agency. Os estudantes eram levados a verificar se seria uma estratégia argumentativa epistêmica asseverativa ou deôntica de obrigatoriedade (must) e/ou possibilidade (should, could), por exemplo.

Já na questão a-9, os alunos são direcionados a refletir sobre a importância do uso dos operadores argumentativos (and, too, because, but), o que seria complementado pela questão 'c', na qual os alunos são solicitados a pensar a respeito da possível intencionalidade do locutor ao utilizar o but como estratégia argumentativa e, posteriormente, com o auxílio do professor, são incentivados a escrever frases com outros operadores, e que poderia resultar nas seguintes opções, rendendo excelentes resultados e discussões em sala de aula:

- This new plan could help people to have a healthier diet BECAUSE they will know how many calories they are eating.

- This new plan could help people to have a healthier diet SO they will lose weight easily.

- This new plan could help people to have a healthier diet AND to start new habits.

Visto isso, comprova-se que o gênero textual em análise, assim como outros opinativos, é propicio para o trabalho com orientações de sentido, ou seja, com argumentatividade. Isto é, o artigo de opinião permite verificar como determinados elementos da língua e do discurso são utilizados para imprimir posicionamentos e direcionamentos e, por isso, é extremamente importante o trabalho com as ferramentas utilizadas pelo locutor ao apresentar seus julgamentos e análises, através da observação dos elementos linguísticodiscursivos.

Chamamos a atenção para o fato de que, em momento algum, pediu-se aos alunos que classificassem esse ou aquele elemento, mas, sim, buscamos sugerir meios que os levem a refletir sobre a sua utilização. Ressaltamos que as questões aqui apresentadas não pretendem se revelar como suficientes, pois sabemos que as possibilidades são inúmeras quando se 
trata do trabalho da habilidade de reading. É importante salientar que os alunos necessitam aprender não só a elencar os argumentos, mas também saber a intenção desses argumentos, além de saber concatená-los e contrapô-los adequadamente. Nesse sentido, assumimos a compreensão de que é no processo de construção do conhecimento a respeito de um conteúdo da aprendizagem que o aluno desenvolve, a partir da mediação feita pelo professor, a capacidade (ou competência) de analisar determinados fenômenos da língua à luz de seus conhecimentos (prévios ou construídos no processo ensino-aprendizagem). Logo, no contexto educacional, a "competência" diz respeito à capacidade do aluno de mobilizar conhecimentos no sentido de resolver determinadas situações apresentadas pelo professor, pelo livro didático etc.

A interpretação de texto, por exemplo, sobre a qual se faz necessária a construção de um olhar reflexivo por parte do aprendiz, não pode ser assumida como decodificação direta. Saber lidar com o conceito de argumentação, seja retórica, seja linguística, e saber identificar o valor semântico de categorias gramaticais como advérbio quanto ao seu papel modalizador, por exemplo, é condição importante para a leitura do texto, todavia não pode ser vista como condição sine qua non. Não estamos inventando novas hipóteses acerca da compreensão linguística; pelo contrário, defendemos a valorização da intuição do aluno, posto que a motivação do ensino reflexivo reside, justamente, no "diálogo" que o aluno precisa ser estimulado a fazer entre conhecimentos conteudísticos e a funcionalidade deles para a apreensão do que se pode fazer com a língua. Desse modo, a aula deve transformar-se em um laboratório de língua e o aluno precisa perceber-se como "cientista da linguagem".

Sabemos que há muito a se contribuir para proporcionar um crescimento na capacidade argumentativa dos nossos alunos, principalmente nas aulas de língua estrangeira, independente da série ou do nível de proficiência, até mesmo porque eles necessitam de atividades de investigação e prática de vocabulário ${ }^{12}$, a fim de auxiliá-los a tornarem-se bastante ativos no processo de aprendizagem, além de desenvolver uma grande variedade de habilidades lexicais, permitindo, assim, que os aprendizes façam uso das palavras de forma mais precisa.

\footnotetext{
${ }^{12}$ Asseveramos sobre a importância das atividades de vocabulário tomando por referência o que propõe Travaglia (2013, p. 251) acerca do ensino de português como língua materna, a saber: “o objetivo geral dos exercícios de vocabulário é fazer que o aluno tenha não um simples conhecimento do sentido das palavras, mas que ele conheça também todas as possibilidades significativas de cada palavra, seus matizes de sentido, as semelhanças e diferenças entre as palavras e expressões e outras relações que as palavras podem ter entre si. É preciso que o aluno saiba perceber o uso do léxico nos textos para compreender sua constituição e formação de seu sentido".
} 


\section{Considerações Finais}

Ao longo deste artigo, procuramos mostrar que o processo de Análise Linguística (nos moldes propostos por Geraldi, 1984) é bastante relevante, além de viabilizar o trabalho com a gramática de língua inglesa, tornando a aprendizagem muito mais significativa e real para os alunos. Além disso, tentamos iniciar a discussão acerca da importância das estratégias argumentativas neste trabalho com o texto, promovendo uma certa fluidez na prática, principalmente, da habilidade de leitura (reading).

Em virtude de ser parte de trabalho que vem sendo realizado pelos Grupos de Pesquisa "Semântica Léxico e Cognição" e "Texto: produção e recepção sob vários olhares"13, os dados aqui apresentados demonstram, mesmo que parcialmente, que o trabalho realizado com as estratégias argumentativas via AL, voltado para o ensino de língua estrangeira, permite e dá oportunidade para que o ensino de gramática continue acontecendo; fato este que pode ser comprovado com as questões que acrescentamos à atividade original do livro didático escolhido, na qual se mostrou a relevância de a argumentação retórica e a linguística serem trabalhadas concomitantemente (ver Quadro 1).

Em suma, o que parece não gerar discussão é que a questão-problema não está no fato de haver uma tradição gramatical nas nossas salas de aula. O problema não está na importância que a metalinguagem e que as atividades gramaticais conferem à compreensão da língua, especialmente em relação à estrutura, passo este extremamente necessário ao aprendiz de uma língua. Existe, todavia, um problema, e ele está na "repetição inconsciente de fórmulas com que suas intuições se escolarizam (no pior sentido de 'escolarização'). Está na falta de reflexão sobre o que realmente se está fazendo, quando fazemos gramática do modo que fazemos" (FRANCHI, 2001, p. 52).

Defendemos, portanto, que um trabalho epilinguístico pode ser efetivado no contexto de ensino de língua estrangeira através do ensino de estratégias argumentativas, possibilitando uma potencialização da capacidade leitora dos estudantes. Para tanto, ressaltamos que antigas crenças e concepções, por parte de alguns docentes e de autores de livros didáticos de língua estrangeira, sejam desconstruídas para dar espaço a uma busca do conhecimento de forma mais constante e consciente. Além disso, é necessário que haja iniciativas governamentais a favor de uma educação de qualidade, ou seja, que tenhamos documentos oficiais norteadores para o ensino de língua (materna ou estrangeira) mais claros e coerentes e que o professor e a escola tenham condições e incentivos para realizar algumas práticas inovadoras.

O ponto de vista adotado por Travaglia (2013), ao qual aderimos, sugere que não é possível atingir letramento real sem que haja foco no significado linguístico, isto é, sem que

\footnotetext{
${ }^{13}$ Disponível em: <https://bit.ly/2ypC3dy $>$.
} 
haja reflexão a respeito das relações de sentido, em que pese uma análise frente à contribuição dos recursos semânticos. Sem esses recursos, o aluno não pode dominar aspectos do trabalho da leitura e da escrita. Perceber que as relações semânticas existentes em gêneros textuais diversos (tais como os apresentados nas atividades de livros didáticos, apenas para relembrar o que fizemos em nossas análises), permitem a compreensão do que se lê, levando o autor a dizer exatamente aquilo a que se propõe, com um sentido específico, requisito fundamental para que o aluno seja um bom produtor e leitor de textos.

Sabemos que a tarefa de ensinar uma língua estrangeira exige dos professores uma constante atualização não só de conhecimentos, mas de postura e atitudes diante da responsabilidade de ensinar uma língua com toda a sua complexidade cultural e semântica a falantes de português (não menos complexa). Mesmo cientes de que outras questões possam ser elaboradas a partir do texto, esperamos que o nosso objetivo de contribuir com as reflexões e no fortalecimento dos estudos e pesquisas na Semântica Argumentativa para o ensino tenha sido atingido, pois com esta proposta intencionamos contribuir com procedimentos que auxiliam o trabalho do professor, propiciando, assim, um ensino de inglês como língua estrangeira mais efetivo.

\section{REFERÊNCIAS}

ALMEIDA, L. de. Análise semântica de operadores argumentativos em textos publicitários. 2001. Dissertação (Mestrado em Linguística) - Universidade Federal de Uberlândia, Uberlândia.

BRASIL. Secretaria de Educação Fundamental. Parâmetros curriculares nacionais: terceiro e quarto ciclos do Ensino Fundamental: língua estrangeira. Brasília: MEC; SEF, 1998.

CABRAL, A. L. T. A força das palavras: dizer e argumentar. São Paulo: Contexto, 2010.

CASTILHO, A. T. de. Nova gramática do português brasileiro. 1. reimp. São Paulo: Contexto, 2010.

CHOPPIN, A. História dos livros e das edições didáticas: sobre o estado da arte. Educação e Pesquisa, São Paulo, v. 30, n. 3, p. 549-566, set./dez. 2004. Disponível em: $<$ https://bit.ly/2EDSCbb>. Acesso em: 15 dez. 2015.

CORBARI, A. T.; RAMOS, Q. C. M. Verbos dicendi na notícia: pontos de um continuum argumentativo na construção da intertextualidade. Fórum Linguístico, Florianópolis, v. 15, n. 1, p. 2903-2923, jan./mar. 2018. Disponível em: <https://bit.ly/2CVzqnx>. Acesso em: 17 ago. 2018.

DUCROT, O. Provar e dižer: linguagem e lógica. São Paulo: Global, 1981. 
DUCROT, O. Esboço de uma teoria polifônica da enunciação. In: DUCROT, O. O dižer e o dito. Campinas: Pontes, 1987. p. 161-218.

DUCROT, O. Polifonia y argumentación: conferencias del seminario Teoría de la Argumentación y Análisis del Discurso. Cali: Universidad del Valle, 1988.

FRANCHI, C. Linguagem - atividade constitutiva. In: FRANCHI, C. Linguagem: atividade constitutiva: teoria e poesia. São Paulo: Parábola, 2001 [1977]. p. 33-74.

GERALDI, J. W. O texto na sala de aula: leitura e produção. 3. ed. Cascavel: Assoeste, 1984.

GERALDI, J. W. Portos de passagem. 4. ed. São Paulo: Martins Fontes, 1997.

KOCH, I. G. V. A inter-ação pela linguagem. 5. ed. São Paulo: Contexto, 2000.

KOCH, I. G. V. Argumentação e linguagem. 13. ed. São Paulo: Cortez, 2011.

KONAR, N. Communication skills for professionals. Nova Deli: PHI Learning Private Limited, 2009.

MELO, J. M. de. A opinião no jornalismo brasileiro. 3. ed. rev. Campos do Jordão: Mantiqueira, 2003.

MENDONÇA, M. Análise Lingüística no Ensino Médio: um novo olhar, um outro objeto. In: BUNZEN, C.; MENDONÇA, M. (Org.). Português no ensino médio e formação do professor. São Paulo: Parábola Editorial, 2006. p. 199-226.

MOURA, H. M. de M. Significaşão e contexto: uma introdução a questões de semântica e pragmática. 3. ed. Florianópolis: Insular, 2006.

NASCIMENTO, E. P. do. Jogando com as vozes do outro: argumentação na notícia jornalística. João Pessoa: Editora Universitária da UFPB, 2009.

NASCIMENTO, E. P. do. A modalização no ensino de língua: contribuições para os processos de leitura, análise linguística e produção textual. In: JORNADA NACIONAL DO GRUPO DE ESTUDOS LINGUÍSTICOS DO NORDESTE, 24., 2012, Natal. Anais... Natal: EDUFRN, 2012. p. 1-13.

NASCIMENTO, E. P. do; SILVA, J. M. da. O fenômeno da modalização. In: NASCIMENTO, E. P. do (Org.). A argumentação na redação comercial e oficial: estratégias semântico-discursivas em gêneros formulaicos. João Pessoa: Editora Universitária da UFPB, 2012. p. 63-100. 
NASCIMENTO, E. P. do; SILVA, R. F. da. O secretariado e a produção textual: a argumentação no gênero declaração. Revista de Gestão e Secretariado, v. 2, n. 2, São Paulo, p. 145-169, 2011.

OXEDEN, C.; LATHAM-KOENIG, C. New English File - Upper Intermediate. Oxford University Press, 2010.

OXEDEN, C.; LATHAM-KOENIG, C.; SELIGSON, P. New English File - Elementary. Oxford University Press, 2010.

PERELMAN, C. O império retórico: retórica e argumentação. 2. ed. Lisboa: Asa, 1999.

SILVA, J. M. da. Modo, modalidade, modalização: autonomia semântico-discusiva em expressões verbais. Revista Prolíngua, v. 7, n. 2, p. 41-58, 2012.

SOUSA, S. C. T. de; SOARES, M. E. O ensino/aprendizagem de língua estrangeira: uma análise à luz das memórias discursivas dos alunos de Letras. Revista de Letras, n. 31, v. 1/2, p. 87-92, jan./dez. 2012. Disponível em: <https://bit.ly/2PcgxT1>. Acesso em: 17 ago. 2018.

TRAVAGLIA, L. C. Na trilha da gramática: conhecimento linguístico na alfabetização e letramento. São Paulo: Cortez, 2013. 